\title{
MODERNIDADE E MODA EM ESAÚ E JACÓ, DE MACHADO DE ASSIS
}

\author{
GEANNETI TAVARES SALOMON \\ Universidade Federal de Minas Gerais \\ Belo Horizonte, Minas Gerais, Brasil
}

Resumo: Este estudo propõe uma análise crítica e literária sobre a modernidade e a moda presentes na obra Esaú e Jacó, de Machado de Assis. Procuro refletir sobre a forma com que o escritor se apropria de realidades sociais cotidianas, relativas à modernidade de seu tempo e à moda, e as imprime nas estratégias de criação literária por meio de fatos reais entrelaçados às suas personagens, criando no espaço ficcional traços marcadamente relevantes para se observarem essas realidades. $\mathrm{O}$ pano de fundo da narrativa é o Rio de Janeiro do século XIX, momento em que ocorrem a crise do Império, a abolição da escravatura e o início da República. A obra permite perceber as relações sociais e profissionais masculinas, bem como o posicionamento da mulher nessa sociedade.

Palavras-chave: modernidade; moda; Machado de Assis; Esaú e Jacó

\section{MODERNITY AND FASHION IN ESAU AND JACOB, BY MACHADO DE ASSIS}

Abstract: This study presents a critical literary study about modernity and fashion in Esau and Jacob, by Machado de Assis. I aim at reflecting on how the writer appropriates everyday social realities concerning the modernity of his time and fashion and prints them in the strategies of literary creation by means of real facts intertwined with their characters, thereby creating markedly relevant features for observing these realities in the fictional space. The background of the narrative is nineteenth century Rio de Janeiro, when the Empire's crisis, the abolition of slavery and the beginning of the Republic occurred. The work reveals the social and professional relationships of men as well as women's status in society.

Keywords: modernity; fashion; Machado de Assis; Esau and Jacob 
Nem casal, nem general. No dia 7 de abril de 1870 veio à luz um par de varões tão iguais, que antes pareciam a sombra um do outro, se não era simplesmente a impressão do olho, que via dobrado.

Esaú e Jacó, Machado de Assis

0 ão tratadas aqui algumas questões recorrentes na obra Esaú e Jacó, de Machado de Assis, lançada em 1904, quatro anos antes da morte do escritor. Dentre as questões, uma mais especificamente e em detalhe: a forma com que o escritor se apropria de realidades sociais cotidianas, relativas à modernidade de seu tempo e à moda, e as imprime nas estratégias de criação literária por meio de fatos reais entrelaçados às suas personagens, criando no espaço ficcional traços marcadamente relevantes para a observação dessas realidades.

O foco aqui é a análise crítica e literária de aspectos constituintes da narrativa que evidenciam como a construção das cenas e das personagens pode ser observada por meio da moda, da indumentária, dos modos e hábitos sociais presentes nessa obra machadiana, bem como dos traços da modernidade do século XIX. Em Esaú e Jacó, a moda vai ser lembrada muitas vezes por meio de seus elementos básicos, isto é, as roupas e acessórios, e, também, enquanto metáfora para aproximar e explicar os fatos da vida, traço bastante peculiar do escritor.

A narrativa tem como pano de fundo, como espaço e tempo, o Rio de Janeiro na segunda metade do século XIX, passando pela crise do Império, a abolição da escravatura e a queda do Império com a entrada da República. Machado de Assis traz para sua história um encadeamento de fatos reais misturados à ficção, por exemplo quando usa datas reais, como no capítulo nomeado "Manhã de 15", no qual conta acontecimentos reais pelo olhar de suas personagens ficcionais, data que se refere a 15 de novembro de 1889, a proclamação da República.

Por meio de relatos o escritor vai contando a história do triângulo amoroso formado por Pedro, Paulo e Flora; os dois rapazes são gêmeos 
parecidos fisicamente, mas completamente opostos em relação ao modo de ver a vida, às convicções políticas, sendo Pedro médico e monarquista, e Paulo, advogado e republicano. A tradição e a modernidade são tratadas por meio dessas personagens antagônicas e suas divergências. Há uma estratégia sutil para sua criação, pois, ao optar por criá-las com diferenças marcantes e também com semelhanças expressivas, Machado de Assis teve que escolher, em determinados momentos, uma abordagem que mantivesse certa coerência frente ao leitor, como procuro expor nas análises apresentadas.

A presença marcante da dicotomia entre o universo de interesses masculinos e femininos é bastante acentuada na obra, na medida em que as mulheres estão muito mais voltadas para as questões de lazer, as domésticas e as afetivas, e os homens mais voltados para as discussões profissionais, públicas, políticas, dentre elas até mesmo o casamento enquanto instituição. Ressalto que essa é uma característica marcante do século XIX e que também aparece em certa medida nas análises que proponho. Pretendo trabalhar, particularmente, com os tipos masculinos do período com o intuito de demonstrar o quão relevante é a manobra de criação das duas personagens Pedro e Paulo.

A modernidade de Machado de Assis sempre foi alardeada pelo fato de que esse grande escritor esteve à frente de seu tempo, com uma visão de mundo bastante aguçada, e foi um leitor voraz da literatura mundial. Foi reconhecido em vida como um dos maiores do Brasil, e o é até os dias de hoje. A grandeza de sua obra e de sua personalidade tem reconhecimento internacional. Essa modernidade está presente em sua obra de diversas formas e, portanto, será um dos pontos que pretendo investigar.

A crítica literária que voltou seus olhos para o período oitocentista procurou avaliar as obras dos escritores brasileiros sob várias perspectivas, mas um ponto importante sempre foi o nacionalismo, ou o que o escritor imprimia da cor local em sua obra. Machado foi avaliado ora positiva ora negativamente em relação a esse quesito, sendo algumas vezes julgado por não se voltar totalmente às questões nacionais, pois se ocupava mais das questões universais, da alma humana e suas contradições, o que certamente vai alcançar as questões cobradas de um escritor nacionalista.

Machado sempre teve muitos críticos, em sua época e posteriormente, e, dentre eles, alguns desafetos. Mas há aqueles que conseguiram mostrar as grandes qualidades do escritor, mantendo certo distanciamento impessoal. 
José Veríssimo, ${ }^{1}$ por exemplo, fez uma leitura do homem Machado de Assis por meio de sua obra. Veríssimo diz que as origens humildes do escritor não foram tema tratado diretamente por este ser avesso a exibicionismos, por ter um espírito recatado e também por ser orgulhoso.

O crítico reconhece em Machado um escritor que foi se aperfeiçoando com o tempo e diz que sua obra conseguiu apresentar a essência da alma humana. O escritor foi "o mais intimamente nacional dos nossos romancistas", justamente por se pensar no nacionalismo não somente como algo que possa ser encontrado "nas exterioridades pitorescas da vida ou nos traços mais notórios do indivíduo ou do meio". 2

Veríssimo também destaca a face ironista de Machado, quando o escritor demonstra grande interesse pela tolice e malícia humanas por meio de uma "imaginação humorística" associada à sua característica visão pessimista e cética. E ainda, principalmente, aponta em Machado uma característica importante: um criador do romance "da vida urbana ou mundana", por tratar em sua obra do cotidiano e do íntimo do homem. Aí está a visão de que o escritor tinha refletida em sua obra uma influência forte do meio social em que viveu.

Para Veríssimo, Machado de Assis e sua obra contêm uma leitura da sociedade e da cultura do século XIX. Também Nelson Werneck Sodré, ${ }^{3}$ outro importante crítico, destaca Machado de Assis como um intérprete do Brasil, um escritor que apresenta o cenário brasileiro por meio de sua obra, mas como interpretação da sociedade e da cultura.

Essa é uma perspectiva importante para o que pretendo desenvolver aqui, pois coloca o escritor Machado de Assis como um grande romancista que escreveu sobre sua época, a modernidade, os costumes de seu tempo, e, sendo assim, os trejeitos de uma sociedade estão explícitos em sua obra. Dentre as ferramentas utilizadas para imprimir essa marca em sua literatura está o uso da moda e da indumentária para delimitar territórios, para realçar aspectos da sociedade, recriando os tipos sociais característicos dessa época, muitas vezes usando a moda como metáfora.

Em seu ensaio "Instinto de nacionalidade", datado de 1873, Machado de Assis ${ }^{4}$ já no título apresenta a questão que considera o traço mais

${ }^{1}$ VERÍSSIMO, História da literatura brasileira: de Bento Teixeira, 1601, a Machado de Assis, 1908.

${ }^{2}$ Idem, p. 284.

${ }^{3}$ SODRÉ, História da literatura brasileira. Seus fundamentos econômicos.

${ }^{4}$ ASSIS, Instinto de nacionalidade \&t outros ensaios. 
característico da literatura brasileira de sua época. O texto analítico reflete a sua obra ficcional: ele observa que tudo serve de inspiração para os poetas e para os prosadores, e que "vestir as cores do país" não pode ser uma ideia que limite o trabalho do artista:

Não há dúvida de que uma literatura, sobretudo uma literatura nascente, deve principalmente alimentar-se dos assuntos que lhe oferece a sua região; mas não estabeleçamos doutrinas tão absolutas que a empobreçam. O que se deve exigir do escritor, antes de tudo, é certo sentimento íntimo, que o torne homem de seu tempo e do seu país, ainda quando trate de assuntos remotos no tempo e no espaço. ${ }^{5}$

Machado afirma ainda que o elemento indígena não é nem deve ser a única fonte de inspiração dos escritores brasileiros, e que esse elemento é tanto nacional quanto universal, como tantos outros assuntos. Ele advoga pela liberdade no processo criativo dos escritores, para que possam usar a diversidade de elementos que quiserem para atingirem, também, o assunto nacional, de forma universal.

\section{Modernidade e moda}

Elizabeth Wilson diz que a modernidade é um período impreciso e um conceito abrangente. A autora aponta dois prismas para se chegar ao termo, mesmo que imprecisamente:

Yet it does always suggest something more precise than simply "everything", and something less narrow than a mere mask for capitalism. It refers to things both intangible and undeniably material: the atmosphere and culture of whole epoch, its smell, its sounds, its rhythm. While an economic analysis may ultimately explain our society more objectively than any other, the use of the term "modernity" makes possible the exploration of our subjective experience of it. ${ }^{6}$

\footnotetext{
5 Idem, p. 17.

${ }^{6}$ Tradução: "No entanto, isso nem sempre sugere algo mais preciso do que simplesmente 'tudo', e algo menos restrito do que uma mera máscara para o capitalismo. Refere-se a coisas, tanto intangíveis quanto inegavelmente materiais: a atmosfera e cultura de uma época inteira, seu cheiro, seus sons, o seu ritmo. Enquanto uma análise econômica pode vir a explicar a nossa sociedade de forma mais
} 
Parece escorregadio esse terreno, mas é nele que pretendo trilhar, pois é bastante produtivo analisar as obras aqui propostas sob essa perspectiva. Machado de Assis traz para suas narrativas essa atmosfera, nas palavras de Wilson, toda a cultura, o cheiro, os sons, o ritmo da modernidade, que tem como prerrogativa a palavra "aceleração", o movimento. Nas obras machadianas encontram-se todo o movimento das classes, os deslocamentos sociais, os encontros e desencontros proporcionados pela convivência próxima/distante das grandes cidades. Essa é a matéria-prima de suas narrativas.

Sobre o conceito de modernidade, importante para entendermos de que tempo e espaço fala Machado de Assis, Wilson diz:

Central to modernity is a paradox: the seventeenth and eighteenth century Enlightenment values of Reason and Science and the defeat of tradition, obscurantist superstition and the perils of what was then termed religious 'Enthusiasm', emerged in tandem which, or as a precursor of, the headlong development of industrial capitalism, which has proved so irrational, so out of control, so unstoppable. For modernity is not defined by Reason, but by speed, mobility and mutability. And, while it always contains the idea of progress and continual forward movement, Theodor Adorno, for example, asserted that it is not chronological at all - although he also objected to the view that it has something to do with zeitgeist. ${ }^{7}$

A autora cita Weber, um dos maiores intérpretes da modernidade, dizendo que este acreditava que a máquina de produção, a industrialização do século XIX, dominava e determinava a vida de toda a sociedade, não apenas nos parâmetros econômicos, mas também em todos os aspectos da

objetiva do que qualquer outra, o uso do termo 'modernidade' torna possível a exploração de nossa própria experiência subjetiva". WILSON, "Fashion and Modernity", p. 9.

7 Tradução: "Há um paradoxo central para a modernidade: o Iluminismo do século XVII e do século XVIII e seus valores da razão e ciência e da derrota do tradicional, o obscurantismo supersticioso e os perigos do que era então chamado de 'entusiasmo' religioso, surgiram em conjunto, ou como precursores, com o desenvolvimento impetuoso do capitalismo industrial, que tem se mostrado tão irracional, tão fora de controle, de modo irrefreável. Não definimos a modernidade pela razão, mas pela velocidade, mobilidade e mutabilidade. E, ao mesmo tempo que ela sempre contém a ideia de progresso e movimento contínuo para frente, Theodor Adorno, por exemplo, afirmou que não é cronológica em tudo - embora ele também tenha se oposto à ideia de que a modernidade tem algo a ver com o espírito da época". Idem, p. 9. 
vida social. Vai lembrar sua metáfora mais famosa: "the iron cage", 8 e apontar a interpretação de During 9 para essa metáfora de Weber como "a casing or housing, as hard as steel", ${ }^{10}$ dizendo que, assim, não há uma gaiola de ferro. Há um fardo, mas sem o qual é impossível viver - o que permite perceber a ambivalência da condição moderna, sendo essa interpretação muito mais próxima do termo "modernidade" do que a metáfora da gaiola.

A modernidade está presente na obra de Machado de Assis, e torna-se notório que o escritor trazia em suas obras todo o "fio social" do período entrelaçado às tramas desenvolvidas em suas narrativas, expressão usada por Candido. ${ }^{11} \mathrm{E}$ essa é uma das características mais atraentes em sua escrita para o estudioso da modernidade e da moda, pois este certamente vai encontrar um vasto arsenal criativo em torno da elaboração das personagens machadianas.

Portanto, claro está que a obra de Machado de Assis reflete toda essa tensão e a ambivalência já apontada, presentes na condição moderna de viver. As relações humanas, com os novos modos de vida urbana e cosmopolita, imprimiram mudanças no cotidiano, sem retorno. Essa ambivalência, o sentimento de fardo que não se quer abandonar, está na sedução que os dispositivos modernos já daquele tempo imprimiram no cotidiano. Assim, o progresso é ambivalente.

A moda é uma característica da modernidade e, para conceituá-la, segue o pensamento de Gilda de Mello e Souza:

A moda é um todo harmonioso e mais ou menos indissolúvel. Serve à estrutura social, acentuando a divisão em classe; reconcilia o conflito entre o impulso individualizador de cada um de nós (necessidade de afirmação como pessoa) e o socializador (necessidade de afirmação como membro do grupo); exprime ideias e sentimentos, pois é uma linguagem que se traduz em termos artísticos. ${ }^{12}$

Esse conceito da autora propõe uma ideia fundante que é a conexão com a sociedade e a cultura, como um fenômeno que busca estabilizar forças antagônicas, que expõe o gosto humano em criar e fazer sentido por meio das

\footnotetext{
8 Tradução: "a gaiola de aço".

${ }^{9}$ DURING, Modern Enchantments, p. 38, apud WILSON, cit., p. 10.

10 Tradução: "um invólucro ou alojamento, tão duro como aço".

${ }^{11}$ CANDIDO, Vários escritos.

12 SOUZA, O espírito das roupas: a moda no século XIX, p. 29.
} 
coisas, dos objetos e dispositivos à sua volta. Assim, a moda não trata somente de vestimentas e acessórios do vestir, sendo também um fenômeno que integra muitas ações humanas, dentre estas as artísticas e políticas.

\section{Tipos masculinos oitocentistas}

É perceptível que as profissões escolhidas e as convicções políticas demarcavam a vida privada e a pública do homem do século XIX. Essas demarcações funcionam, em certa medida, como estereótipos, e em Esaú e Jacó aparecem algumas profissões masculinas relevantes para tornar compreensível o período. São citados o médico, o advogado, o capitalista, o banqueiro e, além desses, os participantes de cargos políticos, como deputados, presidentes, os relacionados às convicções políticas, o monarquista e o republicano, liberal. Na narrativa surgem questões que norteavam a vida masculina do período: Qual profissão deveria escolher? Quem seria a esposa capaz de construir um lar feliz, dando filhos e status para um homem de sucesso? Quais convicções políticas colaborariam para construir uma boa rede de relações? Assim era formado o universo masculino, bastante oposto aos paradigmas femininos estabelecidos.

Flügel ${ }^{13}$ enfatizou "a grande renúncia" masculina em relação à troca de um vestuário mais suntuoso advindo dos séculos anteriores por um vestuário simples, a casaca escura, contando com uma ornamentação mais expressiva nos detalhes do vestuário do que no aspecto geral: o colete, a gravata, o cachimbo, a barba, o relógio, entre outros. Isto é, há uma troca, mostra-se o poder por meio da inteligência, do sucesso profissional de uma carreira, do casamento que contava com uma bela e fútil esposa. O vestuário exagerado dos períodos anteriores, como do Macaroni, por exemplo, fica para trás, já demonstrando então que a seriedade de um homem estava na sobriedade de seu vestuário. Havia o dândi, que aparece também na obra Dom Casmurro, de Machado de Assis. Era uma figura que cultuava a elegância e certa extravagância no vestuário, mas de forma bastante diferenciada dos períodos anteriores.

John Hopkins explica que a Revolução Francesa, no fim do século XVIII, afetou profundamente a moda masculina:

${ }^{13}$ FLÜGEL, Psicologia das roupas. 
Um dos maiores impactos foi o afastamento da ostentação, da decoração luxuosa e do uso extravagante das cores. O chamado "reinado do terror" da Revolução tornou o uso de roupas vistosas e "da moda" um perigo, sendo inevitável um movimento na direção da simplicidade e o abandono da decoração. ${ }^{14}$

Por meio dessas palavras já se pode notar que as condições políticas afetaram profundamente a maneira como o homem se vestiu desde então, e se demonstra que eles são suscetíveis a alterações estéticas relacionadas às suas convicções políticas. Hopkins continua:

O período também marcou o início de um código de vestimenta mais austero para os homens, com predomínio da paleta de azuis, pretos e marrons. Além disso, de acordo com o clima social do período, os homens eram encorajados a se voltarem para as questões mais "sérias" do que aquelas ligadas ao vestir. A moda masculina adquiriu um ar de contenção e sobriedade na nova sociedade, que se tornava rapidamente industrializada. ${ }^{15}$

Era natural que as distinções passassem a ser feitas pelos detalhes do vestuário, pelos acessórios e no aspecto geral do homem, como, por exemplo, a maneira de fazer a barba e o bigode - até mesmo sua ausência, na forma de um rosto liso -, o tipo de bengala, de relógio, o modelo de chapéu, entre outros. Vale ressaltar que as modas e modos europeus eram seguidos fielmente no Brasil do século XIX. As famílias mais abastadas faziam viagens frequentes ao exterior e traziam, além de livros e ideias, o estilo do vestuário e os costumes estrangeiros.

\section{Esaú e Jacó}

As distâncias presentes entre as duas personagens, Pedro e Paulo, são traçadas desde o início da narrativa. Surgem com a visita da mãe dos

${ }^{14}$ HOPKINS, Moda masculina, p. 23.

${ }^{15}$ Ibidem. 
meninos à "cabocla" do morro do Castelo: foi ter com ela para saber do futuro dos filhos pequenos e ouviu um questionamento, se eles haviam brigado antes de nascer, na sua barriga, como as personagens bíblicas que dão nome à obra. E esta diz que não teve uma gravidez tranquila, "que efetivamente sentira movimentos extraordinários, repetidos e dores, e insônias...". E a cabocla vai prenunciando a vida dos meninos, dizendo que serão grandes e felizes, que se briga dentro e fora da barriga: "Cousas futuras!". Natividade, a mãe, pagou com uma "nota de cinquenta mil-réis" que "era cinco vezes o preço do costume". ${ }^{16} \mathrm{E}$ assim, Machado vai delineando os contornos de sua narrativa, dando detalhes não meramente informativos, mas sempre fazendo saltar algo de invisível presente nesses detalhes.

Não fica sem explicação a natureza da fortuna dos pais dos garotos. $\mathrm{O}$ pai, sr. Agostinho José dos Santos, foi pobre, nascido em Maricá, e se mudou "para o Rio de Janeiro por ocasião da febre das ações (1855), dizem que revelou grandes qualidades para ganhar dinheiro depressa". Era diretor de um banco e barão de Santos. Quando se casou com Natividade, ela, aos vinte anos, "não tinha dinheiro, mas era bela". Era "a mais bela mulher daquele tempo". ${ }^{17}$

As contradições são expandidas no decorrer da narrativa, sendo que as pequenas acabam se juntando para amplificar as maiores. Nesse jogo tudo vale para o escritor Machado de Assis, que, com sua habilidade, conduz o leitor, falando com ele diretamente, convidando-o a construir junto a história. O Conselheiro Aires, que viria a ser conhecido por outra obra, Memorial de Aires, aparece como autor de um manuscrito denominado "Último", deixado junto àqueles que compunham o Memorial. Então, como numa matrioska, ${ }^{18}$ o foco narrativo chega ao leitor por meio de um jogo que quer, como em Dom Casmurro e em outras obras do escritor, manipular a verossimilhança. O foco narrativo está em primeira pessoa, "eu" como testemunha, ${ }^{19}$ que se mistura a um narrador onisciente intruso, ${ }^{20}$ pois é livre para narrar, do centro ou da periferia dos acontecimentos, permitindo uma característica bastante evidente em Machado de Assis, que é a visão dúbia do narrador. É um "eu" que fala sendo testemunha, mas por trás dessa escolha

\footnotetext{
${ }^{16}$ ASSIS, Esaú e Jacó, p. 17.

${ }^{17}$ ASSIS, Esaú e Jacó, p. 24.

${ }^{18}$ Série de bonecas russas colocadas umas dentro das outras.

${ }^{19}$ Conforme classificação de Norman Friedman.

${ }^{20}$ LEITE, O foco narrativo.
} 
também está a ironia de que cada um possui a sua verdade, jogando com a ideia de verdade absoluta. Essa é a voz narrativa adotada em Esaú e Jacó. Segue aqui um exemplo da presença desse narrador:

Não me peças a causa de tanto encolhimento no anúncio e na missa, e tanta publicidade na carruagem, lacaio e libré. Há contradições explicáveis. Um bom autor, que inventasse a sua história, ou prezasse a lógica aparente dos acontecimentos, levaria o casal Santos a pé ou em caleça de praça ou de aluguel; mas eu, amigo, eu sei como as coisas se passaram, e refiro-as tais quais. ${ }^{21}$

No excerto vemos o narrador se colocar apenas como quem observa, ironicamente dizendo que não inventa sua história, trazendo também o leitor "amigo" para a conversa. Também diz sobre "a lógica aparente dos acontecimentos", ironicamente abrindo ao leitor o fazer literário como um construto, e vai tensionar essa lógica, testando o imaginário do seu leitor, que ele quer bastante arguto.

Ao longo da narrativa são demarcados os terrenos sociais masculinos e femininos. Aos rapazes, as questões profissionais que norteiam o sucesso. Assim que os meninos nasceram os pais já sonhavam com médicos, advogados, engenheiros, e ainda a marinha e os ministérios foram pensados. Quando ainda não tinham barbas, um sintoma de certa maturidade para o sexo masculino, as convicções políticas começaram a aparecer, e Machado traz para a trama de Esaú e Jacó uma grande questão de seu tempo: as novas tendências políticas liberais que alcançaram a Corte brasileira com mais intensidade na segunda metade do século XIX. A narrativa se passa nessa época e é composta com o pano de fundo da crise do Império brasileiro, a abolição da escravatura e a queda do Império, com a entrada da República.

Ao tratar desse aspecto da sociedade, o escritor vai abranger várias outras questões que envolvem a moda, como os bailes, as reuniões sociais, os passeios públicos, as cerimônias, as diferenças entre as classes, seus hábitos e modos de vestir; e as modas políticas, termo que usa em um capítulo quando ocorre exatamente a queda do Império e o dono da "Confeitaria do Império" não sabe se muda o nome da placa para "Confeitaria do Governo",

${ }^{21}$ ASSIS, cit., p. 25, grifo nosso. 
"Confeitaria do Custódio", concluindo junto ao Conselheiro Aires que é melhor esperar "um ou dois dias, a ver em que param as modas". 22

Em Esaú e Jacó há passagens que vão claramente apontar para esse "sinal de novos tempos". Em relação aos dois jovens gêmeos, Paulo e Pedro, e suas convicções políticas precoces, o narrador diz que os dois nasceram no dia 7 de abril de 1870, e Paulo afirma: "Nasci no aniversário do dia em que Pedro I caiu do trono". E Pedro afirma: "Nasci no aniversário do dia em que Sua Majestade subiu ao trono". ${ }^{23}$ Paulo era considerado pela mãe como um subversivo, rebelde, e sempre foi motivo de preocupação por isso. Temia pelo futuro do filho, que era contra o regente. O narrador explica:

As barbas não queriam vir. Por mais que eles chamassem o buço com os dedos, mas as opiniões políticas e outras vinham e cresciam. Não eram propriamente opiniões, não tinham raízes grandes nem pequenas. Eram (mal comparando) gravatas de cor particular, que eles atavam ao pescoço, à espera que a cor cansasse e viesse outra. Naturalmente cada um tinha a sua. Também se pode crer que a de cada um era, mais ou menos, adequada à pessoa. ${ }^{24}$

Machado de Assis tem como característica marcante utilizar traços da moda, detalhes do vestuário, de forma deslocada, depositando-lhes uma nova significação, sem perder aquela de origem. No caso da citação acima, a gravata é uma peça que distingue o homem do período de várias maneiras. $\mathrm{O}$ volume, a proporção em relação ao pescoço e à pessoa que a usa, o material de que é produzida, o padrão, a forma, enfim, tudo condiz para reputar o homem oitocentista. A gravata traz identidade para quem a usa. E assim, também pode ser usada como metáfora para as contradições políticas dos gêmeos, querendo acentuá-las ao máximo, um importante acessório do universo masculino que eram tanto as gravatas quanto as convicções políticas. E diz que "naturalmente" cada um tinha a sua, querendo acentuar aí que havia semelhanças e diferenças, apesar de se tratar de gêmeos.

Em outro capítulo, Machado expõe a importância do chapéu, e isso se dava tanto para homens quanto para mulheres. Flora, a moça por quem os gêmeos se interessam, sai com sua mãe para comprar "encomendas", pois vão

${ }^{22}$ Idem, p. 150.

${ }^{23}$ Idem, p. 61.

${ }^{24}$ Ibidem. 
se mudar para o Norte, uma nomeação de seu pai, Batista, para um posto público de presidência, em plena crise do Império. O narrador diz que "Tudo são instrumentos nas mãos da Vida", 25 referindo-se ao fato da saída à rua do Ouvidor que toma outro rumo, sendo esse local um importante centro comercial e de moda, que trazia todos os objetos de necessidade e de desejo da sociedade fluminense:

As duas saíram de casa, uma lépida, a outra melancólica, e lá foram a escolher uma quantidade de objetos de viagem e de uso pessoal. D. Cláudia pensava nos vestidos da primeira recepção e de visitas; também ideou o do desembarque. Tinha ordem do marido para comprar algumas gravatas. Os chapéus, entretanto, foram o principal artigo da lista. Ao parecer de d. Cláudia, o chapéu da mulher é que dava a nota verdadeira do gosto, das maneiras e da cultura de uma sociedade. Não valia a pena aceitar uma presidência para levar chapéus sem graça, dizia ela sem convicção, porque intimamente pensava que a presidência dá graça a tudo. ${ }^{26}$

Na sequência desses acontecimentos Flora se encontra com Paulo, o estudante de Direito que morava em São Paulo, e os dois mundos são resumidos pela conversa que travam: "[Paulo] Contava anedotas de S. Paulo, sem grande interesse para Flora; as notícias que ela lhe dava acerca das amigas eram mais ou menos dispensáveis. Tudo valia pelos dois interlocutores". ${ }^{27}$ Assim, eram distintos os interesses, o masculino voltava-se para o público, e o feminino para o privado. Às mulheres, os ambientes domésticos, as saídas às compras, os enfeites; aos homens, a vida profissional, os estudos, as viagens. Essa separação entre interesses masculinos e femininos também aparece em outras passagens, como por ocasião de uma recepção na casa dos gêmeos, que permite ver também a formação do triângulo amoroso:

Mais de uma vez, Pedro deu com ela fitando Paulo, e gemeu com a preferência, mas também ele era preferido depois, e achava compensação. [...] Pouco a pouco, a gente se foi dispersando. Não era muita, e dominava a nota íntima. Quando a maioria saiu, ficou só a

\footnotetext{
${ }^{25}$ Idem, p. 133.

${ }^{26}$ Idem, p. 134.

${ }^{27}$ Idem, p. 135.
} 
porção mais íntima, três ou quatro homens a um canto da sala, falando e rindo de ditos e anedotas. Não conversavam de política, e aliás não faltaria matéria. As moças, pela segunda ou terceira vez, trocavam as impressões do grande baile recente. Também falavam de músicas e teatros, das festas próximas de Petrópolis, da gente que ia naquele ano, e da que iria só em janeiro. ${ }^{28}$

Flora se sente dividida entre as atenções dos irmãos, que acabam disputando-a, revelando o jogo de sedução também tão característico do período, no qual a mulher se mantinha atenta à corte do pretendente, enquanto este fazia as investidas. Mas em uma passagem fica a ideia de que elas faziam a escolha: "é certo que vocês gostam dela, e igualmente certo que ela ainda não escolheu entre os dois". ${ }^{29}$

Os dois irmãos "gêmeos eram belos e continuavam parecidos" ${ }^{\prime 30}$ quando adultos, de acordo com o narrador. Havia "graças comuns". ${ }^{31}$ É interessante perceber que Machado de Assis opta por não descrevê-los em detalhes físicos ou em relação ao seu vestuário. Isso é intrigante, pois o escritor, em sua obra anterior, Dom Casmurro, utiliza claramente o vestuário como estratégia de criação literária que leva à ironia, de forma a demarcar características entre a Capitu mulher e a Capitu menina. São criadas ambiguidades que colaboram para a construção de uma personagem tão deslizante como Capitu, descrita na voz de um narrador muito bem arquitetado por Machado de Assis. Há também muitos descritivos importantes de outra personagem, José Dias. ${ }^{32}$

Em Esaú e Jacó há a intenção de demarcar as diferenças internas às personagens, isto é, suas convicções políticas opostas, seus modos de ver a vida, como no excerto: "A razão parece-me ser que o espírito de inquietação reside em Paulo, e o de conservação em Pedro". ${ }^{33}$ Mas as diferenças externas, que certamente também poderiam ser uma escolha do escritor, não aparecem.

Buscando compreender essa escolha, podemos pensar em algumas opções e a mais concebível, enquanto estratégia de criação literária, é a

\footnotetext{
${ }^{28}$ Idem, p. 139.

${ }^{29}$ Idem, p. 200

${ }^{30}$ Idem, p. 193.

${ }^{31}$ Idem, p. 194.

32 SALOMON, Moda e ironia em Dom Casmurro.

${ }^{33}$ ASSIS, cit., p. 244.
} 
ausência do descritivo do vestuário para dar a ênfase necessária às diferenças internas. Se o escritor optasse por descrever o vestuário de cada um, mesmo que de forma sutil, certamente seria para distingui-los, já que os mesmos buscavam essa distinção, de acordo com a narrativa. $O$ narrador diz que eles "trocavam de armas para continuar o duelo"; ${ }^{34}$ portanto, a ausência de um descritivo da aparência dessas duas personagens, tendo as diferenças internas tão demarcadas propositadamente, permite que eles continuem "o duelo".

Isso pode ser percebido ao analisar a espécie de loucura na qual Flora envereda. No capítulo "Fusão, difusão, confusão", Flora passa a ter alucinações que a levam a unificar os dois moços em uma só pessoa. Na presença de um sentia alegria, mas também tristeza pela ausência do outro, e vice-versa. Se as ideias políticas contrárias e todo o resto relativo ao comportamento fossem transpostos para o vestuário e os acessórios das personagens, certamente estes se distanciariam um do outro também na aparência, mas isso seria inconsistente para a manutenção da ideia de que eram iguais por fora e diferentes por dentro, básica na construção da estrutura da obra.

Portanto, haveria uma incongruência em relação à constituição dessas personagens, e o escritor a resolve justamente pela falta dessa descrição. Sua ausência é uma escolha intrigante, e brilhante.

\section{Considerações finais}

De muitas maneiras Esaú e Jacó é uma obra-prima de Machado de Assis. Nela o escritor trabalha várias características suas que foram elaboradas ao longo de toda a sua carreira literária. Há um primor no uso do foco narrativo, que acontece em cascata, sendo a voz de uma personagem importante como a do Conselheiro Aires, trazida de outra obra, e a voz de um narrador intruso. E existe esse efeito de duplicidade de personagens, mas que se querem diferentes, antagônicas, contrastantes. A intertextualidade também é empolgante, levando o leitor iniciado a se deleitar com as possibilidades das muitas janelas que se abrem, e a mais óbvia delas está no título da obra.

${ }^{34}$ Ibidem. 
E ainda, a forma com que os aspectos marcantes de uma época, seu cheiro, seu som e seu ritmo, a moda e a modernidade do século XIX aparecem misturados entre fatos reais e ficcionais, estratégias literárias que encantam tantos leitores na atualidade.

\section{Referências}

ASSIS, Machado de. Esaú e Jacó. Porto Alegre: L\&PM, 1998.

—. "Instinto de nacionalidade". In: ASSIS, Machado de. Instinto de nacionalidade \&t outros ensaios. Porto Alegre: Mercado Aberto, 1999, p. 9-36.

CANDIDO, Antonio. "Esquema de Machado de Assis". In: Vários escritos. 4. ed. reorg. pelo autor. Rio de Janeiro: Ouro sobre Azul; São Paulo: Duas Cidades, 2004, p. 13-32.

FLÜGEL, John C. Psicologia das roupas. Tradução de Antônio Ennes Cardoso. São Paulo: Mestre Jou, 1966.

HOPKINS, John. Moda masculina. Porto Alegre: Bookman, 2013.

LEITE, Lígia Chiappini Moraes. O foco narrativo. São Paulo: Ática, 1981.

SALOMON, Geanneti Tavares. Moda e ironia em Dom Casmurro. São Paulo: Alameda, 2010.

SODRÉ, Nelson Werneck. História da literatura brasileira. Seus fundamentos econômicos. 5. ed. Rio de Janeiro: Civilização Brasileira, 1969.

SOUZA, Gilda de Mello e. O espírito das roupas: a moda no século XIX. São Paulo: Companhia das Letras, 2001.

VERÍSSIMO, José. História da literatura brasileira: de Bento Teixeira, 1601, a Machado de Assis, 1908. Intr. de Heron de Alencar. 4. ed. Brasília: Editora Universidade de Brasília, 1981.

WILSON, Elizabeth. "Fashion and Modernity". In: EVANS, Caroline. Fashion and Modernity. Edited by Christoper Breward and Caroline Evans. New York: Berg, 2005. 
GEANNETI TAVARES SALOMON é doutoranda no Programa de Pós-Graduação em Estudos Literários da Universidade Federal de Minas Gerais, POSLIT FALE/UFMG. Mestre em Literaturas de Língua Portuguesa, pela PUC Minas/Capes; graduada em Letras/PUC Minas, com extensão em Estilismo e Modelagem do Vestuário/UFMG. Área de pesquisa acadêmica: Moda e Literatura. Participa do grupo de pesquisa Mito e Modernidade, FALE/UFMG. Autora do livro Moda e ironia em Dom Casmurro, Alameda (2010), e de artigos científicos e capítulos de livros publicados. Tem experiência profissional em criação de Moda, Figurino e Produção de Moda. Leciona no curso de Moda do Centro Universitário UNA, disciplinas Produção de Moda, Figurino, História da Moda, TCC projeto, entre outras. E-mail: gntavares@gmail.com. 